\title{
Managing COVID-19 Pandemic Crisis: The Case of Greece
}

\section{Neofytos Aspriadis' ${ }^{10}$}

1. Visiting Research Fellow, Department of Political Studies and International Relations, University of Peloponnese, Corinth, Greece

\begin{abstract}
This qualitative study analyzes the Greek government's crisis management practice and public communication efforts during two waves of the COVID-19 pandemic in 2020. Integrating both crisis management theories and the World Health Organization's pandemic control plans, discourse analysis and case study approaches were taken to analyze how Greek's key government and public health authorities communicated with the public using different frames and crisis response strategies. Evaluations were conducted to assess the Greek government's crisis communication procedures and the effectiveness of different rhetorical strategies used as evidenced in public briefings and public speeches.
\end{abstract}

KEYWORDS: Pandemic Management, Greece, Covid-19 communication management, crisis communication, image restoration

It has already been a year since March 2020 when the World Health Organization (WHO) announced the spread of a new strain of coronavirus from Wuhan City, Hubei, in 114 countries worldwide, declaring the COVID-19 epidemic a pandemic (WHO, 2020). The rapid escalation and global spread of COVID-19 have prompted governments to implement policies and measures to manage virus transmission and give health systems time to prepare for and mitigate the impact of the pandemic (Haberstaat et al., 2020; Hale et al., 2020).

CONTACT Neofytos Aspriadis (D) · E-mail: asprto@gmail.com • Department of Political Studies and International Relations • University of Peloponnese - Damaskinou \& Kolokotroni, Damaskinou • Korinthos 201 00, Greece 
This paper examines the crisis management strategies used by the Greek government in response to the spread of the COVID-19 pandemic in Greece. The article focuses on the nonpharmaceutical interventions (NPIs) of pandemic management and does not take into consideration the medical aspects like vaccine development or medical treatment. In addition, it examines the crisis communication procedures and the rhetorical strategies used by the Greek authorities.

The theoretical framework of the study draws on crisis management theory and practice-based models of the WHO and evaluates the management of the pandemic during the two major waves in Greece (i.e., March and November 2020). Through the comparison of both waves, the study aims to examine the strategies and evaluate the models used for both phases by the Greek Government. The findings add to the growing literature on effective crisis response strategies for COVID-19 pandemic management (Christensen \& Lægreid, 2020; Habersaat et al., 2020; Hale et al., 2020; Manokara et al., 2020) and show the close relation of crisis management and non-pharmaceutical interventions (NPIs) of pandemic management.

The first section contains the theoretical part including crisis management theory, pandemic management theory, and practicebased models of the WHO and formulates a combination of both theoretical and practical models. The final section examines the case study of Greece and its overall pandemic management throughout the two major COVID-19 waves in Europe.

\section{Literature Review and Theoretical Frameworks}

\section{Crisis Management}

Crises come in many shapes and forms. Conflicts, human-made accidents, and natural disasters chronically shatter the peace and order of societies (Boin et al., 2005). Typically, they are defined as untimely, but predictable events (Heath \& Millar, 2004, p. 33) that include the element of surprise (Richardson, 1994), and generally marks a phase of disorder in the seemingly normal development of a system (Boin et al., 2005). Besides, they create high levels of 
uncertainty and threat or perceived threat to an organization's high-priority goals (Seeger et al., 1998).

Crisis management is the approach an organization takes to handle emerging troubles and rapidly emerging issues of contention, risk, disasters, accidents, emergencies, and characteristically uncontrollable problems (Bowen \& Lovari, 2020). There are several models of effective crisis management and communication (e.g., Coombs, 2004; Coombs \& Holladay, 2002, 2008; Hearit, 2006; Heath, 1998; Pearson \& Mittroff, 1993). Some relate the crisis with the attribution of responsibility that emerges from the crisis itself or stakeholders (Coombs, 2004; Coombs \& Holladay, 2002, 2008), whereas others focus more on mitigating or minimizing the challenges and damages caused by the crisis (Benoit, 1995; Dezenhall, 2011; Gilbert \& Lauren, 1980; Hearit, 2006; Heath, 1998).

A crisis unfolds through three main stages: the pre-crisis phase, the crisis phase, and the post-crisis phase (Bowen \& Lovari, 2020). Those three main phases form the crisis cycle. The pre-crisis phase involves the prevention of, and preparation for, crises in order to minimize damage to the organization (Coombs \& Laufer, 2018). "It allows time to research and plan for broad types of crises so that response can be expedited" (Bowen \& Lovari, 2020, p. 3). Therefore, issues management is a process that helps organizations to search and early detect problems and proceed to preemptive resolutions (Bowen \& Lovari, 2020; Heath, 2002, 2018).

Although issues management in the pre-crisis phase cannot always prevent a crisis from happening, the main objective is to minimize or mitigate the risks or negative effects of a potential crisis (Coombs \& Holladay, 2010). Subsequently, risk assessment and management contribute to the timely identification of the potential danger an event can bring, so that it can be managed on time (Comfort, 2007; Rickard et al., 2013; Sellnow et al., 2017).

The crisis phase represents the response to the crisis, including the organization's response and the response of its stakeholders (Coombs \& Laufer, 2018). There are several crisis management models like Heath's (1998) 4R model where the four "R's" represent a stage: Reduction, Readiness, Response, and Recovery. Diers-Lawson's (2017, 2020) Stakeholder Relationship Model, 
which emphasizes the role of stakeholders during a crisis and the management according to their attitudes. Coombs's $(1998,2007)$ Situational Crisis Communication Theory and Benoit's (1995) Image Restoration Theory focus mainly on the reputational and communicational aspect of a crisis but can also be implemented in general crisis management procedures, especially in situations that evolve attribution of blame. These models cover both communicational and operational crisis management.

Effective crisis management can be summarized in five basic strategic steps: (a) the timely identification of the type of crisis, where and when it is possible (Coombs, 2014; Diers-Lawson, 2017, 2020); (b) the swift reduction of the main crisis effects (Heath, 1998); (c) damage control (Dezenhall, 2011) in case the situation becomes or is already uncontrollable; (d) narrative control through strategic communications (An et al., 2010; Benoit, 1995; Coombs, 2007; Hearit, 2006); and (e) building resilience against crisis regeneration (Heath, 1998).

\section{Pandemic Crisis Management Strategies and WHO's Practice-Based Model}

This section focuses on pandemic management strategies from literature and practice-based models and combines them to shed further light on the general crisis management theory and practice.

According to Pan and Meng, "Health crises appear to be increasingly preoccupied with invisible, unpredictable, and uncontrollable risks in a global society" (2016, p. 95). Globally, human populations are more urbanized, which may allow viruses to be transmitted within populations more easily (Reissmann et al., 2006). Pandemics and epidemics are proven to be a threat to countries because they may produce megacrises like the COVID19 pandemic. A pandemic example apart from COVID-19 is the $\mathrm{H}_{1} \mathrm{~N}_{1}$ influenza pandemic, a global outbreak of a new influenza A virus, completely different from the previous ones (Centers for Disease Control and Prevention [CDC], 2016).

Pandemics occur when a new virus emerges that can easily infect humans and spread from person to person in an effective and permanent way; very few are going to be immune and there is 
no vaccine available (CDC, 2016; WHO, 2018a). Until a vaccine or effective treatment becomes available, public behavior and adherence to national and subnational response strategies-notably social, physical, and social distancing measures-will continue to be key measures for controlling the virus (Habersaat et al., 2020).

Especially during a pandemic period given the limited response time, dynamic infectious conditions, and intense public pressure, lead health agents are supposed to be capable of sensemaking, evaluating the nature and scope of the pandemic, and searching for an appropriate response (Lai, 2012). During the SARS outbreak contact tracing as well as other strategies like the involvement of the public in maintaining good health habits reinforced a sense of control in an otherwise difficult and confusing time (Tiong, 2004). The management and dissemination of public information during any crisis are critical (Glantz, 2014).

Pandemic crisis management mainly depends on the epidemiological data provided by scientists and the main operational response measures are directed by the capacity of a country's healthcare units. Limiting the basic reproductive number, or the number of secondary infections from an ill person, is a tremendous opportunity for local communities (Glantz, 2014, p. 563). Epidemiological models for monitoring the evolution of the pandemic (e.g., Froese, 2020; Luo, 2020) determine the operational crisis management measures a government needs to implement.

In the pandemic crisis management literature as well as in the practice-based models of the WHO, the non-pharmaceutical interventions (NPIs) include restrictions and reductions of social gatherings and crowds, restrictions of movement, the closing of department stores, bars, commentary, university institutions, as well as public awareness campaigns on hand hygiene, use of protective equipment and observance distances in social gatherings (Bell et al., 2009; Cadogan \& Hughes, 2021; Peng, 2008; Reynolds \& Quinn Crouse, 2008). The CDC and WHO's plans have primarily focused on detection and disease control through (1) surveillance and early detection, (2) community containment strategies (movement restrictions, facility closure, and healthcare service continuity) that would decrease disease transmission, and 
(3) mass prophylaxis strategies using vaccines and antiviral medication, when available (Reissman et al., 2006).

More severe measures include travel restrictions and the closure of the borders (Cadogan \& Hughes, 2021; Manokara et al., 2020). Containment measures may prevent transmission, or at least suppress or slow the spread of a pandemic, allowing time for targeted use of medical interventions (Reissman et al., 2006). During the COVID-19 outbreak in 2020 most of those NPI measures were taken by most countries to contain and delay the transmission of the virus (Cadogan \& Hughes, 2021). NPIs serve to delay the spread of infection, buy time, decrease the total number of infections, and reduce the spread of infection by each individual (Glantz, 2014, p. 563).

The WHO has developed a series of plans and proposals for pandemic management (WHO, 2018a, 2018b, 2019a, 2019b). The WHO's model (2010a, 2018a) for influenza pandemic management is divided into six main phases which follow the model of phases of development of a pandemic influenza crisis (WHO, 2010a). According to this model (WHO, 2010a), the first phase concerns the quiet period before the outbreak of a disease. The second and third phase involves detecting a virus that has been transmitted from animals to humans and poses a potential pandemic threat without, however, having sufficient human-to-human transmission capable of causing an outbreak at the community level. The fourth phase is characterized by the confirmation of the ability of the disease to spread from person to person who can cause spread in the community. The ability of the disease to spread in the community is a significant risk increase for developing a pandemic, but it does not mean that it is certain or inevitable. In the fifth phase, the human spread affects at least two countries in one geographical area. Finally, a pandemic begins by an outbreak at the community level in at least one country other than the geographical area of the virus's origin. The last two phases concern the phase of de-escalation of a pandemic crisis (WHO, 2010b).

\section{Combining Theory and Practice for Pandemic Management}

The general pandemic model of WHO is being combined with the crisis management theory. The WHO model shows the stages for 
the development of a pandemic. On the other hand, crisis management theory includes models that elaborate on management processes in each crisis stage. The combination of both models may provide insights that help identify the effective and timely application of pandemic management strategies based on the pandemic crisis cycles and crisis management procedures. For example, issue management is a delayed response when a crisis has entered its main phase. Respectively, precautionary measures like obligatory masks or contact tracing as a main measure during the heat of the crisis would be an ineffective approach.

The first three phases of the WHO pandemic model are being identified with the corresponding pre-crisis phase of crisis management, which contains issues management and search for potential risks or threats. A pandemic environmental monitoring and regular risk assessments are of high importance to regulate the transmission rate and fortify the health system of a country. The main crisis phase relates to phases 4-6 of the WHO pandemic model, where the identification of human transmission has been confirmed, while there is a significant spread in the community. The sixth phase is a particular turning point in a pandemic crisis, in which a disease is widely spread and somewhat uncontrollable. Crisis management at this level requires the application of strict NPIs as a damage control strategy. Resilience building can be identified with the possibility of mass vaccination or fortification of the health system.

Grounded in pandemic management theory and practice, this study explores the following research questions:

RQ1: What were the main pandemic containment measures used in managing the first and the second waves of the COVID-19 pandemic in Greece?

RQ2: What were the differences between the first and the second waves of pandemic management in Greece in terms of crisis management and crisis communication?

RQ3: What were the main (a) rhetorical strategies and (b) dominant frames used by Greek authorities for crisis communication management during the two pandemic waves? 


\section{Methodology}

The methodology used is qualitative content analysis with elements from rhetorical and discourse analyses. Qualitative content analysis is appropriate for a relatively small amount of textual matter (Krippendorff, 2004; Van Evera, 1997). Besides, qualitative content analysis allows the liberty of viewing the case from the inside out and seeing it from the perspective of those involved (Gillham, 2000). The qualitative content analysis was mainly used to identify the NPI strategies used for the containment of COVID-19, drawn from the official Greek governmental internet pages (i.e., gov.gr, eody.gr, and covid19.gov.gr).

The rhetorical analysis focuses on how messages are delivered and with what effects (Krippendorff, 2004). For this reason, it was used in the examination of the crisis communication discourse of three main crisis management authorities. However, the analysis did not focus on argumentation building but on rhetorical strategies through the examination under existing rhetorical typologies and tools. Therefore, discourse analysis, especially political discourse analysis (Filardo-Llamas \& Boyd, 2018), was also applied. In particular, the pre-existing typologies and rhetorical tools used for the analysis included framing theory and the image restoration theory by Benoit (1995) that consists of five main strategies to avoid blame or restore one's image (i.e., denial, evading responsibility, reducing offensiveness, corrective action, and mortification).

The crisis communication analysis was conducted on (1) speeches from daily press briefings of two main public figures at the front line of the Greek government's pandemic communication: President of the Experts Committee, Professor Sotiris Tsiodras; Undersecretary of Civil Protection and Crisis Management Nikos Chardaliasand and (2) the regular official addresses from the Prime Minister, Kyriakos Mitsotakis, gathered during the first and the second waves of COVID-19 pandemic management in Greece. The time frame of the research was from March 3 until May 4, 2020 (Wave 1), and from the end of September until the end of October 2020 (Wave 2). A total of 60 transcripts of the 
press briefings containing the speeches of Professor Tsiodras and Undersecretary Chardalias with the Q\&A section as well as the public addresses of the Prime Minister Mitsotakis were analyzed. A total of 388 rhetorical strategies were coded and analyzed.

\section{Case Study: Managing COVID -19 Pandemic Crisis in Greece}

\section{Managing the First Wave of COVID-19 Pandemic in Greece Pre-Crisis Phase}

The first wave of COVID-19 arrived in Greece almost 2 months after the outbreaks reported in China in January 2020. From January 22, Greece entered the pre-crisis phase where issues and risk management measures were taken. Until mid-February 2020 the Greek Ministry of Health monitored the situation in China. The risk of imminent contamination in Greece was very low at that time; therefore, the measures taken focused mostly on preparations in case an infected person was identified.

During this preparatory phase, an expert committee of epidemiologists was established to monitor the situation and to advise the government. At the end of February, given the outbreak situation in Italy, the danger for Greece became very imminent. The National Organization of Public Health (EODY) applied contact tracing for the cases coming from Italy when a person developed symptoms. The organization also issued an information package advising regular temperature testing to those who traveled recently and developed a list of countries that were at risk.

Since the imported cases from Italy were unavoidable, the Greek Government suspended all carnival festivities that were programmed until March 7. Furthermore, the Ministry of Public Health published a series of information regarding personal protection against coronavirus, the 13 reference hospitals throughout the country, and the new telephone line of EODY for the coronavirus with a $24 / 7$ operation (Onmed.gr, 2020). The suspension of carnival events together with the informative measures prepared the citizens psychologically and informatively for the impending crisis and saved time for an uncontrollable outbreak. 


\section{Main Crisis Phase}

The first confirmed case of COVID-19 in Greece was reported on February 26; however, the main crisis phase began after the return of a tourist group from Israel (Iefimerida.gr, 2020). From that point on, the situation evolved rapidly. On March 16, the Secretary-General of General Secretariat for Civil Protection Nikos Chardalias was promoted to the Undersecretary of Civil Protection and Crisis Management and became head of the operational aspect of the COVID-19 crisis. The newly appointed Undersecretary joined the press briefings together with the President of the Experts Committee, Professor Sotiris Tsiodras, steadily at 6:00 every afternoon to inform the public on the evolution of the outbreak. The professor focused on the medical developments concerning the pandemic and the Undersecretary on the governmental decisions and the operational crisis management measures.

The main goal of the government at that time was "to save time to further strengthen the national health system, and to protect the most vulnerable" (Petsas, 2020). The initial measures taken for that purpose included the closure of all educational institutions, the suspension of any kind of conferences and events that gather more than 1,000 people, the prohibition of sport events gatherings, and strong advice on hygiene measures at any gathering of more than 50 people.

Two days later, on March 13, the implementation of the measure "We Stay Home" began. All citizens are invited to stay at home as long as possible and go out only when necessary. At the same time, special permits were given to working parents, so that they could take care of their children at home and avoid contact with their grandparents, who belong to vulnerable groups.

On March 22, in a televised public address, the Prime Minister Mitsotakis announced his decision to proceed with "a prohibition on all unnecessary movement of citizens throughout the territory" (Mitsotakis, 2020). Citizens needed to have a special permit by SMS or signed by themselves which included only six reasons for leaving their house. In essence, this permission was not given by an official government body nor was its truthfulness checked by the authorities but was more an enhancement of the "individual 
responsibility." An absence of the document or the SMS would result in a fine.

The severe lockdown measures were maintained for 6 weeks and included school closure; distance working; and closure of all marketplaces, bars, cafés, and the international borders. In the meantime, a lot of public services went digital to facilitate transactions with the public sector.

The lockdown measures were stricken toward the Easter holidays, where people were expected to move to nearby villages or holiday homes. The measures included a strong justification for the reason for movement and prohibition of domestic travels. Besides, police controls rose during the holidays. The main reason was to avoid further spreading of the virus to the provinces since until that time the main spread of the disease was restricted in the two big cities of Greece, Athens and Thessaloniki.

\section{Crisis Communication}

In parallel with the operational crisis management measures undertaken during the first coronavirus outbreak in Greece, a major communication campaign was established to inform the public about the threat and danger of COVID-19. The communication was centrally planned and executed. As the crisis unfolded, the daily Press Briefings held by Professor Tsiodras and Undersecretary Chardalias became a routine in the everyday life of the lockdown citizens.

These regular press briefings were important communication and managerial tools which showed the Greek citizens the constant presence of the state and potentially acted as a stress reliever for the situation. Besides, the profile of Professor Tsiodras became a symbol of leadership in the crisis management process and quickly gained the trust of the citizens. Nevertheless, for serious decisions and changes in strategy, Prime Minister Mitsotakis directly addressed the public about the situation and the decisions made and actions taken by the government.

Furthermore, the communication slogan of "We Stay at Home/ Menoume Spiti" with the logo ${ }^{1}$ (showing a nice, lovely home), was liked by the public and immediately began to circulate by all TV

1. "We Stay Home” Logo: https://menoumespiti.gr/ 
channels. In effect, the General Secretariat of Civil Protection took effort in developing strategic messaging and advertisements to inform the public of the new everyday life and precautionary measures that the people must take. In the advertisements beloved TV actors or doctors participated to give the right tone to the message. ${ }^{2}$

The strategic communication messaging was very coherent among the three main frontline figures: Prime Minister Mitsotakis, the President of the Expert Committee Professor Tsiordas, and Undersecretary of Civil Protection Chardalias. Prime Minister Mitsotakis represented the political side of the crisis management procedure giving a tone of unity; Undersecretary Chardalias represented the decision-making body, and the executive aspect of crisis management; and Professor Tsiodras represented the scientific and medical aspects of management. Besides, the latter tried to promote a more human profile during the press briefings, most likely due to his character, which helped convince the public to listen to him and maximize the approval rating for the crisis management procedure institutionalized by government authorities.

The main frames that were mobilized rhetorically during the whole time of the main crisis were the war frame, and the individual social responsibility frame. The War Frame was introduced by the Prime Minister in his first address to the public on March 11.

\footnotetext{
"We are at War! With an enemy that is invisible but not invincible. Because if we succeed to limit the transmission of the virus, we can give time to our Health System to deal with the emergency calls." (Mitsotakis, March 11, 2020)
}

Words like "frontline," "enemy," "weapons against the virus," "battle," "sacrifices," "target," and metaphors as "forts of life" constructed the semantic ecology of the war frame. The political managers (Prime Minister Mitsotakis and Undersecretary Chardalias) used both the war frame; however, not in the same capacity. Prime Minister Mitsotakis used it as his main strategic frame, whereas Undersecretary Chardalias used it as a support frame. Professor Tsiodras, on the other hand, did not use this frame almost at all.

2. Civil Protection Information Kit: https://www.civilprotection.gr/en/media-gallery 
The individual social responsibility frame was being used by all three leading public figures/leading authorities during their public briefings on the pandemic. Contrary to the war frame, this individual frame seems to be the main frame used by Professor Tsiodras and Undersecretary Chardalias. This frame included mainly a call to the citizens to protect their hygiene and keep social distancing to limit the spread of the disease. Indirectly through this frame, Prime Minister Mitsotakis pointed out the citizens as the primary safeguards of national health.

It all depends on us all and our behavior whether the government needs to take even more drastic control measures. (Mitsotakis, March 19, 2020)

Consequently, this frame was often used to blame directly or indirectly individual citizens and the general public for not following the public health measures to contain the spread of the disease.

Also, at this point, I want to emphasize that any discussion or various excuses for moving during those days (means the eastern vacations), is a completely irresponsible and anti-social attitude and I want to explain why ... (Chardalias, April 7, 2020)

Nevertheless, the individual responsibility frame was used by Professor Tsiodras more as an incentive to motivate the public and offer an explanation for the reasons why social distancing is vital for the containment of the virus spread and why social responsibility is a sign of freedom.

Our collective thinking, so as not to burden the neighbor with the spread of the virus, not to overload the health structures, is and remains in the coming weeks our main goal. The virus ( . . ) reminds us that free societies thrive on rules of social responsibility. (Tsiodras, April 6, 2020)

This frame was used almost under the same conditions by all three leading authority figures. The rhetorical justification of the frame was threefold: (a) Ideology: Democracy and Freedom as vital parts of the Western society "demand" the participation of the citizens and thus social responsibility; (b) Hygiene-practical 
use: social responsibility as a pandemic containment measure; (c) Scapegoat-blame shifting accusing those who do not follow the precautionary measures as socially irresponsible and dangerous for society.

The only way to protect our loved ones, our way of life, our neighborhoods, our homeland, is the path of individual responsibility. And that means one thing: we follow the instructions. We stay at home. We faithfully apply the rules of hygiene. (Chardalias, March 16, 2020)

Another strategy used frequently by the three main crisis actors was the strategy of bolstering. All three public figures used this strategy to praise both the work of the government

The Government will do everything necessary, when necessary and often earlier than necessary. Nevertheless, believe me: No massive measure can replace individual responsibility. And in our open democratic societies, no central decision works, unless it is shared first by all citizens. (Mitsotakis, March 11, 2020)

\section{and the quick reaction of measures taken}

The government is facing an unprecedented crisis. And it reacted quickly. (Mitsotakis, March 13, 2020)

as well as to praise the people for practicing "social responsibility" or for the healthcare workers for doing a good job.

And I want to thank them (the healthcare workers), once again, on behalf of all the citizens. Our biggest gain, however, from this unprecedented crisis has a name. And it's called Trust. Trust in the State, the Government the fellow citizen! Because, in 50 days, myths of decades were dispelled. And conclusions were drawn, which will accompany us for a long time. It has been shown, for example, that the state must be evaluated primarily based on its effectiveness. And that, when the state does not become a slave of power, then it becomes a real "State." (Mitsotakis, March 13, 2020)

The strategy of bolstering was used several times by all three main public health authority figures in almost all their speeches and press briefings. The main aim, as can be concluded, was to bolster their image or the image of the government to show strength 
and liability to the institutional pandemic management. There are several explanations for its frequent use. Comparing bolstering strategy with the individual social responsibility frame, it provides strategic advantage by emphasizing on the one hand, the government has done anything in its power to manage the crisis; on the other, it is the people's responsibility to follow the measures and remain healthy. This way, the government tries to construct, preemptively, a possible scapegoat to shift the blame for a possible failure in the future. Another explanation for the frequent use of bolstering strategy may lie with the past failures of governments' attempts of handing public crises, which indicated the need of restoring the image of the government in order to gain the trust of the people.

The first pandemic wave in Greece practically ended with the easing of lockdown measures after May 4. During the Summer (May-October) of 2020, the cases were kept low, and it was possible to fully reopen the economy. This interim crisis phase consisted of the post-crisis phase of the first wave and the early pre-crisis phase of the second wave.

\section{Managing the Second Wave of COVID-19 Pandemic in Greece Pre-Crisis Phase}

The second wave began in October when suddenly the cases began to increase rapidly. Nevertheless, this time the problem occurred only when the intensive care units began to increase. The difference with the first wave can be summarized in that living with COVID19 became normal and the healthcare system was strengthened to deal with more cases. This led to a more relaxed pre-crisis phase compared to the first wave.

October was the pre-crisis month. Although precautionary measures should have been taken, the first new measures to stop the spread during the second wave came only in mid-October when the government announced the obligatory use of masks everywhere. At that time, the daily confirmed cases were around 300-400 a day according to EODY. However, as the numbers increased the circumstances also changed. The situation got out of hand particularly in northern Greece. At the end of October, 
the reported cases reached almost 3,000 a day, putting enormous pressure on the health system, especially in northern Greece.

\section{Main Crisis Phase}

The main crisis stage came from Northern Greece when Thessaloniki (the second-largest city in Greece) and Serres, a nearby city, witnessed a major outbreak. On November 3 the country was divided into two zones: to the regions with imminent danger and with excessive danger. For the latter, the lockdown measures imposed included closing of theaters, businesses, restaurants, borders, and free movement to and from without any excuse or a justified reason. For the regions in the imminent danger zone, the restaurants and theaters closed but other retail businesses and shops remained open.

Two days later and as the situation escalated, a general lockdown for the whole country was decided. Beginning on November 7 and for almost 3 weeks (initially planned but was extended later) everything closed except for schools, which closed eventually 1 week later, and free movement was prohibited without an SMS or special license. Until that time the main message of the government was the denial of a potential lockdown.

The severe measures were taken too late and could not stop the spread in time. In Northern Greece, hospitals were on the edge and patient transportation to other cities including Athens was deemed necessary. In addition, the pre-crisis phase was not exploited in taking mild measures in time to avoid deteriorating the situation.

\section{Crisis Communication}

Communication during the second wave was slightly different than the first. The press briefings returned to a regular basis in October. However, Professor Tsiodras did not return, and other members of the committee took his role in a rotation. Prime Minister Mitsotakis addressed the public four times from the end of September until the announcement of the general lockdown at the beginning of November. 
These slight changes in the communication strategy of the government together with the adaptation of the citizens to the pandemic lifestyle contributed to minimizing the public's feeling of an upcoming second crisis. The rotational change of the epidemiologists in the press briefings also minimized the coherence of the messages and the effects of continuity to the first wave, including the connection/identification with leadership figures as well as the cohesion of the government strategic communication.

In the second wave of the COVID-19 pandemic in Greece, the strategic orientation of the messages slightly differed in the speeches given by Prime Minister Mitsotakis. The war frame, which was the master frame during the first wave period in his speeches, was replaced by the individual social responsibility frame. The reason for that change was apparently the fact that during the pre-crisis phase in October the basic response strategy was to mobilize the citizens to keep the precautionary measures to avoid the spread of the disease and eventually a lockdown.

To enhance the frame but also to highlight a new risk for the upcoming crisis, the Prime Minister Mitsotakis used strategies of rhetorical risk increase.

After a long period of stability, the cases are increasing exponentially in our country as well. And scientists warn that, soon, the new pandemic will shake the resilience of the National Health System. Challenging not only patients but also our doctors and nurses. (Mitsotakis, October 31, 2020)

However, the main rhetorical strategy used by Prime Minister Mitsotakis during the second wave of the pandemic was the strategy of bolstering/self-praise. This time, this strategy was implemented in an apologetic/image restoration manner in order to bolster the image of the government and address all the criticism that was initiated against it either from the citizens (e.g., masks denial movements) or the political opposition (accusation of mismanagement of the secondary crises and other measures like school opening).

The government, I remind you, is fighting on many fronts at the same time: National issues, Immigration, Economy, but also natural 
disasters. But especially in the war for health, we need the conscious citizen as an ally more than anywhere else. (Mitsotakis, Sept. 24, 2020)

The strategy of bolstering also aimed to enhance the image of the prime minister himself mainly to restore the trust in his figure as a leader and crisis management authority as it was during the previous wave of the pandemic.

I have proved, after all, that I do not hesitate to make difficult decisions quickly. But in order to tame the new wave of the pandemic, the state, scientists and citizens must work even more closely, with more trust in each other. (Mitsotakis, Sept. 24, 2020)

A new input in the strategic communication of the prime minister is the increased use of a new frame, the frame of hope. This frame was used more frequently than in the first wave, where it was almost absent in the public briefings.

I will close, however, with an optimistic message. Because for the first time since the beginning of this adventure, the prospect of having a safe and effective vaccine appears on the horizon. And the government has made sure we get it on time, and make it available to everyone, as quickly as possible. At the same time, the flu vaccination is proceeding according to plan. (Mitsotakis, Oct. 22, 2020)

The hope frame was used to motivate the public to show resilience and patience for the second wave. The storytelling of an imminent "happy ending" of the pandemic would give the citizens strength to follow the measures for some more time. Especially during the lockdown in November, the press briefings included the publication of the government plans regarding the vaccination process which would begin in January 2021.

In sum, Prime Minister Mitsotakis's discourse, during this period, forms the strategy of transcendence. Apparently, the failure to effectively manage the pre-crisis phase of the second wave of the health crisis led to a second general lockdown, which was considered a failure due to the burden of secondary crises. The increased use of bolstering strategy (especially self-praise) shows that the prime minister tried to restore his image toward society in an attempt to transcend from explaining why the situation got 
from "We are far away from a lockdown" (Chardalias, Oct. 16, 2020) to the imposition of a lockdown 15 days later.

\section{Discussion}

In light of RQ1, the findings show that the basic pandemic management tool used in both pandemic waves in Greece was a severe lockdown, including all the economic activities that related to gatherings in public places and prohibition of unnecessary movement. Distance working from home was imposed for all administrative and service-related staff. A slight difference between the two pandemic waves was the imposition of obligatory masks in all public places during the second wave.

Although the same measures were imposed in both waves, the second was considered a more serious one. One reason might be the late imposition of containment measures and the absence of precautionary measures during the initial phase of the crisis in early to mid-October. This suggests a failure in the proper identification of the crisis phases.

Regarding RQ2, the findings suggest that during the first wave, Greece seemed to have taken advantage of all the crisis phases, drawing up action plans early on, and aimed to prevent a large and uncontrolled influx of cases. Damage control strategies like the closure of all activities that contained gatherings were taken during the main crisis phase. Strategies were adjusted when necessary according to the environmental scanning. This way, Greece managed to prevent the spread by being one step "ahead of the disease." At the same time, the government increased the resilience of the health system, preparing for worst-case scenarios.

At the communication level, during the first wave of the pandemic in Greece, the ongoing information campaigns in the media, as well as the cohesive strategic communication message at the daily press briefings by the same crisis managers, increased the level of trust by the public, limiting the spread of fake news and disinformation. The crisis management objective was clearly communicated from the beginning during the first wave. On the contrary, during the second wave, the delayed response, or the total absence of precautionary measures before the cases got out of 
control, led to a more severe crisis. Furthermore, the government authorities' crisis communication during the second wave failed to inform the citizens of the state of emergency at the pre-crisis phase. Reassuring messages misinformed the citizens on the real situation. Besides, the rotation of the experts' committee representatives in the press briefings led to the weakening of the strategic communication messaging. The objective, this time, was not clearly defined and communicated based on the data analyzed.

As far as RQ3 is concerned, the main rhetorical strategy (RQ3a) used was the bolstering/self-praise which aimed at the enhancement of the leadership image and the defense of the measures taken by the government. The dominant frames (RQ3 $b$ ) were the war frame, and the individual social responsibility frame. During the first wave, the war frame was dominant, whereas, during the second, the individual social responsibility frame took its predominant place. The change shows that the aim of Greek public health authorities was to mobilize the citizens to keep the protective measures and to avoid a lockdown.

Consequently, the findings of this study suggest that the first wave was managed more effectively than the second one. The change in decisive variables such as leadership communication and failure of following the crisis cycle vigilantly affected Greek government's pandemic management outcomes. As this study argues, early management measures would have prevented an uncontrolled escalation of the pandemic during the second wave.

A fundamental limitation of the study is the examination of the managerial process in only one country, where the same government handles two discrete crises caused by two surges of COVID-19 cases. Another limitation is the absence of supportive medical and epidemiological data that could provide important additional variables. Future research may focus on comparative studies with more countries to get more evidence on a broader overview of effective pandemic management. Besides, follow-up studies should be carried out, based on and expanding the current research framework, to further understand the ongoing evolution of the crisis management of the pandemic in Greece and other countries throughout 2021. 


\section{ORCID}

Neofytos Aspriadis (ㄷ) https://orcid.org/oooo-0002-3458-8952

\section{References}

An, S. K., Park, D. J., Cho, S., \& Berger, B. (2010). A crosscultural study of effective organizational crisis response strategy in the United States and South Korea. International Journal of Strategic Communication, 4(4), 225-243. https://doi.org/10. 1080/1553118X.2010.515543

Bell, D. M., Weisfuse, I. B., Hernandez-Avila, M., Del Rio, C., Bustamante, X., \& Rodier, G. (2009). Pandemic influenza as 21st century urban public health crisis. Emerging Infectious Diseases, 15(12), 1963-1969. https://doi.org/10.3201/ eid1512.091232

Benoit, W. (1995). Accounts, excuses and apologies, a theory of image restoration strategies. State University of New York Press.

Boin, A., Hart, P., Stern, E., \& Sundelius, B. (2005). The politics of crisis management: Public leadership under pressure. Cambridge University Press.

Bowen S. A., \& Lovari A. (2020) Crisis management. In P. Harris, A. Bitonti, C. Fleisher, A. Skorkjær Binderkrantz (Eds.), The Palgrave Encyclopedia of Interest Groups, Lobbying and Public Affairs. Palgrave Macmillan. https://doi.org/10.1007/978-3030-13895-0_18-1

Cadogan, C. A., \& Hughes, C. M. (2021). On the frontline against COVID-19: Community pharmacists' contribution during a public health crisis. Research in Social and Administrative Pharmacy, 17(1), 2032-2035. https://doi.org/10.1016/j. sapharm.2020.03.015

CDC. (2016). Pandemics basics. https://web.archive.org/ web/20201101184811/ttps://www.cdc.gov/flu/pandemicresources/basics/index.html

Christensen, T., \& Lægreid, P. (2020). Balancing governance capacity and legitimacy: How the Norwegian government handled the COVID-19 crisis as a high performer. Public Administration Review, 8o(5), 774-779. https://doi.org/10.1111/puar.13256 
Comfort, L. K. (2007). Crisis management in hindsight: Cognition, communication, coordination, and control. Public Administration Review, 67, 189-197. https://doi.org/10.1111/ j.1540-6210.2007.00827.x

Coombs, W. T. (1998). An analytic framework for crisis situations: Better responses from a better understanding of the situation. Journal of public relations research, 10(3), 177-191. https://doi. org/10.1207/s1532754xjprr1003_02

Coombs, W. T. (2004). Impact of past crises on current crisis communication: Insights from situational crisis communication theory. Journal of Business Communication, 41(3), 265-289. https://doi.org/10.1177/0021943604265607

Coombs, W. T. (2007). Protecting organization reputation during a crisis: The development and application of situational crisis communication theory. Corporate Reputational Review, 1o(3), 163-176. https://doi.org/10.1057/palgrave.crr.1550049

Coombs, W. T. (2014). Ongoing crisis communication: Planning, managing, and responding. Sage Publications.

Coombs, W. T., \& Holladay, S. J. (2002). Helping crisis managers protect reputational assets: Initial tests of the situational crisis communication theory. Management Communication Quarterly, 16(2), 165-186. https://doi.org/10.1177/089331802237233

Coombs, W. T., \& Holladay, S. J. (2008). Comparing apology to equivalent crisis response strategies: Clarifying apology's role and value in crisis communication. Public Relations Review, 34(3), 252-257. https://doi.org/10.1016/j.pubrev.2008.04.001

Coombs, W. T., \& Holladay, S. J. (2010). The handbook of crisis communication. Willey-Blackwell.

Coombs, W. T., \& Laufer, D. (2018). Global crisis managementCurrent research and future directions. Journal of International Management, 24(3), 199-203.https://doi.org/10.1016/j.intman .2017 .12 .003

Dezenhall, E. (2011). Damage control: The essential lessons of crisis management. Prospecta Press. 
Diers-Lawson, A. (2017). Crisis communication. In M. S. Croucher, C. Zeng, D. Rahmani, \& M. Sommier (Eds.), Oxford research encyclopedia of communication. Oxford University Press.

Diers-Lawson, A. (2020). Crisis communication: Managing stakeholders relationships. Routledge.

Filardo-Llamas, L., \& Boyd, M. S. (2018). Critical discourse analysis and politics. In J. Flowerdew \& J. E. Richardson (2018). The Routledge handbook of critical discourse studies (pp. 312-327). Routledge.

Froese, H. (2020). Infectious Disease Modelling: Fit Your Model to Coronavirus Data. Medium. https://towardsdatascience. $\mathrm{com} /$ infectious-disease-modelling-fit-your-model-tocoronavirus-data-2568e672dbc7

Gilbert, A. N., \& Lauren, P. G. (1980). Crisis management: An assessment and critique. Journal of Conflict Resolution, 24(4), 641-664. https://doi.org/10.1177/002200278002400405

Gillham, B. (2000). Case study research methods (Continuum research methods). Continuum.

Glantz, E. J. (May 2014). Community crisis management lessons from Philadelphia's 1793 epidemic. ISCRAM 2014 Conference Proceedings-11th International Conference on Information Systems for Crisis Response and Management, 556-564.

Habersaat, K. B., Betsch, C., \& Danchin, M. (2020). Ten considerations for effectively managing the COVID-19 transition. Nature Human Behavior, 4, 677-687. https://doi.org/10.1038/ s41562-020-0906-X

Hale, T., Boby, T., Angrist, N., Cameron-Blake, E., Hallas, L., Kira, B., Majumdar, S., Petherick, A., Phillips, T., Tatlow, H., \& Webster, S. (2020). Variation in government responses to COVID-19. Blavatnik School of Government Working Paper, December 10. www.bsg.ox.ac.uk/covidtracker

Hearit, M. K. (2006). Crisis management by apology corporate responses to allegations of wrongdoing. Lawrence Erlbaum Associates Publishers.

Heath, R. L. (1998). Crisis management for managers and executives. Pitman Publishing. 
Heath, R. L. (2002). Issues management: Its past, present, and future. Journal of Public Affairs, 2(4), 209-214. https://doi. org/10.1002/pa.114

Heath, R. L. (2018). Issues management. In R. L. Heath and W. Johansen (Eds.), The International Encyclopedia of Strategic Communication. Wiley-Blackwell.

Heath, R. L., \& Millar, D. P. (2004). Responding to crisis. Lawrence Erlbaum Associates.

Iefimerida.gr (2020). Coronavirus: 21 new cases in GreeceFrom the group of Israel visit. https://web.archive.org/ web/20200306104541/https://www.iefimerida.gr/ellada/ koronoios-21-nea-kroysmata-stin-ellada-agioi-topoi

Krippendorff, K. (2004). Content analysis: An introduction to its methodology. Sage Publications.

Lai, A. Y. (2012). Organizational collaborative capacity in fighting pandemic crises: A literature review from the public management perspective. Asia-Pacific Journal of Public Health, 24(1), 7-20. https://doi.org/10.1177/1010539511429592

Luo, J. (2020). Predictive monitoring of COVID-19. Working draft. Singapore University of Technology and Design.

Manokara, R., Van Sant, K., \& Hanley, M. (2020). Strategic communications in crisis: How East Asian governments responded to the COVID-19 pandemic. NATO Strategic Communications Center of Excellence.

Mitsotakis, K. (2020, March 22). Public Address to the People. https://primeminister.gr/2020/03/22/23615

Onmed.gr. (2020). First coronavirus case in Greece-The health of the 38-year-old woman from Thessaloniki. https://web.archive. org/web/20200323114336/https://www.onmed.gr/ygeiaeidhseis/story/382180/proto-kroysma-koronaioy-stinellada-38xroni-gynaika-sti-thessaloniki

Pan, P. L., \& Meng, J. (2016). Media frames across stages of health crisis: A crisis management approach to news coverage of flu pandemic. Journal of Contingencies and Crisis Management, 24(2), 95-106. https://doi.org/10.1111/1468-5973.12105 
Pearson, C. M., \& Mitroff, I. I. (1993). From crisis prone to crisis prepared: A framework for crisis management. Academy of Management Perspectives, 7(1), 48-59. https://doi.org/10.5465/ ame.1993.9409142058

Peng, Z. (2008). Preparing for the Real Storm during the Calm: A Comparison of the Crisis Preparation Strategies for Pandemic Influenza in China and the U.S. Journal of Homeland Security and Emergency Management, 5(1).

Petsas, S. (2020, March 11). Press Briefing of Political editors by the Governmental representative. https://media.gov.gr/ienimerosi-ton-politikon-syntakton-apo-ton-kyvernitikoekprosopo-stelio-petsa-13-3-2020/

Reissman, D. B., Watson, P. J., Klomp, R. W., Tanielian, T. L., \& Prior, S. D. (2006). Pandemic influenza preparedness: Adaptive responses to an evolving challenge. Journal of Homeland Security and Emergency Management, 3(2), 1-26. https://doi. org/10.2202/1547-7355.1233

Reynolds, B., \& Quinn Crouse, S. (2008). Effective communication during an influenza pandemic: The value of using a crisis and emergency risk communication framework. Health Promotion Practice, 9(4 Suppl), 13-17. https://doi. org/10.1177/1524839908325267

Richardson, J. L. (1994). Crisis diplomacy. Cambridge University Press.

Rickard, L. N., McComas, K. A., Clarke, C. E., Stedman, R. C., \& Decker, D. J. (2013). Exploring risk attenuation and crisis communication after a plague death in Grand Canyon. Journal of Risk Research, 16(2), 145-167. https://doi.org/10.1080/1366 9877.2012 .725673

Seeger, M. W., Sellnow, T. L., \& Ulmer, R. R. (1998). Communication, organization, and crisis. In M. E. Roloff (Ed.), Communication Yearbook 21. Sage.

Sellnow, D. D., Lane, D. R., Sellnow, T. L., \& Littlefield, R. S. (2017). The IDEA model as a best practice for effective instructional risk and crisis communication. Communication Studies, 68(5), 552-567. https://doi.org/10.1080/10510974.2017.1375535 
Tiong, T. N. (2004). Crisis theory and SARS: Singapore's management of the epidemic. Asian Pacific Journal of Social Work, 14(1), 7-17. https://doi.org/10.1080/21650993.2004.9755939

Van Evera, S. (1997). Guide to methods for students of political science. Cornell University Press.

World Health Organization (WHO). (2010a). Current WHO phase of pandemic alert for Pandemic $\left(\mathrm{H}_{1} \mathrm{~N}_{1}\right)$ 2009. https:// web.archive.org/web/20100823043204/https://www.who.int/ csr/disease/swineflu/phase/en/

World Health Organization (WHO). (2010b). What is post-pandemic? https://web.archive.org/web/20121022030636/https:// www.who.int/csr/disease/swineflu/frequently_asked_questions/post_pandemic/en/

World Health Organization (WHO). (2018a). Essential steps for developing or updating a national pandemic influenza preparedness plan.

World Health Organization (WHO). (2018b). A practical guide for developing and conducting simulation exercises to test and validate pandemic influenza preparedness plans.

World Health Organization (WHO). (2019a). Pandemic influenza preparedness in WHO Member States.

World Health Organization (WHO). (2019b). Strategic Preparedness and Response Plan.

World Health Organization (WHO). (2020). WHO DirectorGeneral's opening remarks at the media briefing on COVID-1911 March 2020. https://web.archive.org/web/20201025053458/ https://www.who.int/director-general/speeches/detail/whodirector-general-s-opening-remarks-at-the-media-briefingon-covid-19---11-march-2020 